\title{
Os valores Civilizatórios e o jogo Mancala como possibilidade de resgate e valorização da Cultura Quilombola
}

\section{The civilization values and Mancala Game as a possibility of rescue and promotion of Quilombola Culture}

\author{
Ernani Luis Vitorazzi de Freitas (ernanif@atceee.com.br) \\ Universidade Federal do Rio Grande do Sul (UFRGS) \\ Leandra Anversa Fioreze (leandra.fioreze@gmail.com) \\ Universidade Federal do Rio Grande do Sul (UFRGS)
}

\author{
Claudia Luisa Zeferino Pires (claudia.luisapires@gmail.com) \\ Universidade Federal do Rio Grande do Sul (UFRGS)
}

\begin{abstract}
Resumo: O Quilombo dos Alpes, localizado na cidade de Porto Alegre - RS, é um local de resistência e resgate dos valores histórico-ancestrais que são afirmados na convivência entre as gerações. A pesquisa do tipo participante visa responder como o jogo Mancala pode ser utilizado como recurso pedagógico para instigar a reflexão sobre os valores civilizatórios afro-brasileiros, e quais desses valores são percebidos pelos jovens e crianças. A Mancala é uma família de jogos de tabuleiro que reproduz o ato de semeadura e colheita, prática ancestral distribuída em todo o continente africano. Os sujeitos da pesquisa são exclusivamente crianças e jovens pertencentes à comunidade, participantes do cotidiano das famílias autodeclaradas quilombolas. Concluiu-se que a Mancala pode ser utilizada associada à apresentação dos valores civilizatórios da população negra com o propósito de valorizar e de reconhecer a importância de seus saberes e fazeres, e que a inserção se configurou como uma oportunidade de ação educativa que visa contribuir com a formação para um mundo menos desigual.
\end{abstract}

Palavras-chave: Mancala; Comunidade Quilombola; Jogos; Valores Civilizatórios.

\begin{abstract}
Quilombo dos Alpes, located in Porto Alegre, RS, Brazil, is a site of resistence and rescue of ancient-historical values which are asserted on the coexistence between generations. The participative research attempts to answer how Mancala Game can be used as pedagogical resource to inspire the reflection about Afro-Brazilian civilization values and which of those values are noticed by young people and children. Mancala is a family of board games that reproduces the act of seeding and harvest, ancient practices widespread around the African continent. The research subjects are exclusively young people and children belonging to the community and also people related to theroutine of the self-declared quilombola families. It was concluded that Mancala Game might be used in association with the presentation of the Afro-Brazilian community civilization values to promote and recognize the importance of its knowledge. That insertion has also turned into an educative opportunity to contribute to the reduction of the world inequality.
\end{abstract}

Key words: Mancala; Quilombola communities; Games; Civilization Values. 


\section{INTRODUÇÃO}

A decisão por uma pesquisa em comunidade quilombola é por si só uma ação social, política e ideológica. Social porque acontece na presença e em benefício da coletividade, política porque negociada com suas lideranças, e ideológica porque articulada com fundamentos que reconhecem a necessidade de conferir maior visibilidade às ações de valorização da cultura africana e afro-brasileira.

O Quilombo dos Alpes, um autodeclarado quilombo urbano desde 2005, é um lugar de resistência e de resgate dos valores histórico-ancestrais que são afirmados pela convivência e interação entre as gerações que o compõe. Este quilombo localiza-se entre os bairros Teresópolis e Cascata em Porto Alegre, nos altos do morro dos Alpes, sendo considerado o maior quilombo urbano do município, com área aproximada de 58 hectares, considerando que a cidade possui sete Quilombos Urbanos reconhecidos pela Fundação Palmares (DOBLAL, 2005). A figura 1 apresenta a localização no município de Porto Alegre.

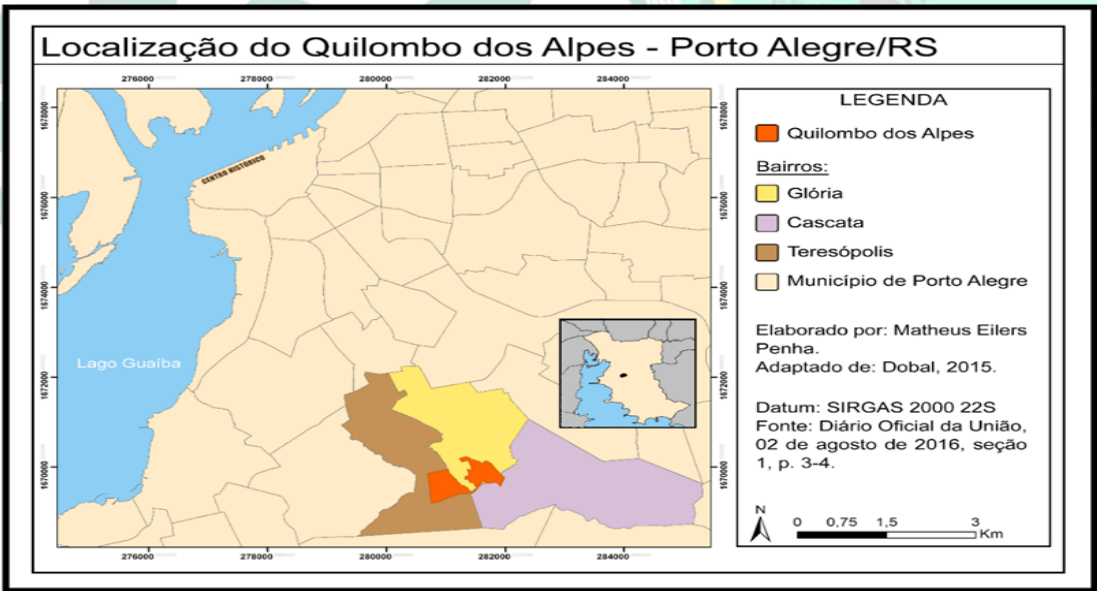

Figura 1- Localização do Quilombo dos Alpes Fonte - NEGA, 2018

A história do Quilombo dos Alpes está associada a chegada de Edwirges Garcia da Silva - a Vó - no morro dos Alpes no começo do século XX. A Vó Edwirges assentou-se no morro e permaneceu por toda sua vida, tecendo trilhas ancestrais que grafam as vivências e as caminhadas quilombola pelo morro dos Alpes. Os percursos da presença e da permanência quilombola iniciado a partir da Vó atravessa as várias 
gerações de seus descendentes que ainda hoje vivem e conservam este lugar, que carrega a estratégica função na expansão territorial da cidade de Porto Alegre em direção a zona sul da cidade. O Quilombo dos Alpes é um território que está integrado às relações entre sociedade e natureza, materializadas e subjetivadas por ações que reconstituem saberes e a diversidade de apropriações espaciais presentes na paisagem e na organização comunitária e nas relações espaciais (DOBLAL, 2005).

Atualmente vivem aproximadamente 120 famílias pelo território quilombola e a presidente da associação dos moradores do Quilombo dos Alpes é Rosangela da Silva Ellias (conhecida como Janja). Na associação ocorrem diversas atividades do Quilombo, como a capoeira, reuniões, oficinas recreativas e educacionais. É neste local que geralmente abriga os eventos realizados pelos moradores, como os bailes dançantes e festas comunitárias. $\mathrm{O}$ ambiente da associação recebe as crianças cotidianamente, onde são realizadas diversas atividades. Tem-se, nessa utilização da associação, a intenção de pensar a Escola Quilombola e propiciar, através do uso diário do espaço, práticas coletivas e de educação.

É neste contexto que esta pesquisa tem como foco a possibilidade de utilização do jogo Mancala como indutor de reflexões sobre a dimensão da cultura afro-brasileira num ambiente não escolar de valorização da cultura negra, o Quilombo dos Alpes. Desenvolvemos uma pesquisa participante com crianças e jovens quilombolas onde, através de uma ação lúdica com o jogo Mancala, buscamos identificar como este jogo pode ser utilizado como recurso pedagógico para instigar a reflexão sobre os valores civilizatórios afro-brasileiros e quais os valores são identificados pelos mesmos no seu cotidiano.

\section{A FAMÍLIA MANCALA}

Mancala é uma família de jogos de tabuleiro que tem origem presumida na África, composta por uma grande variedade de nomes e de regras, disseminada especialmente no continente africano e nos países asiáticos. Os árabes provavelmente foram os responsáveis pela transmissão aos países do mundo islâmico, onde muitas variações são conhecidas.

O nome Mancala tem raízes árabes com o significado de movimento. Segundo Pereira (2011), no continente africano encontram-se os registros mais antigos de sua prática, com datações estimadas de até sete mil anos. 
O jogo reproduz o ato de semeadura e colheita (que é uma prática ancestral distribuída em todo o continente africano), e pode ser jogado mesmo diretamente no solo, não requerendo necessariamente tabuleiros ou peças elaboradas. Em geral são utilizadas sementes sobre um campo de jogo composto por 12 cavas menores alinhadas em duas fileiras, ao lado das quais se posicionam duas cavas maiores, que alguns denominam como oásis (figura 2). Cada jogador ocupa uma linha de cavas com quatro sementes em cada uma delas. O objetivo do jogo é reunir a maior quantidade possível de sementes em seu oásis, que em seu início não tem nenhuma.

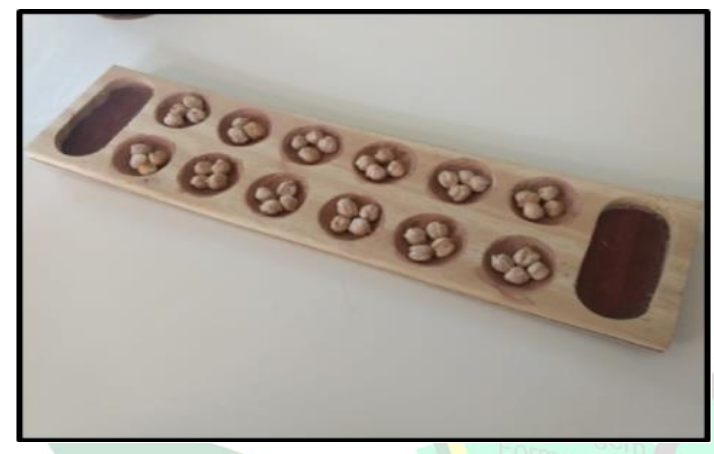

Figura 2 - Tabuleiro e sementes para jogar MANCALA.

Fonte - Autor

Dentre as diversas variações do jogo, nos fixamos naquela denominada Ayo, ou

Ware, Owalé, Kalah ou Kalaha, que possui origem Nigeriana e cujas regras são utilizadas em diversas versões de jogos para computador ou celulares. Nesta versão, a cada rodada o jogador da vez escolhe uma cava de seu campo de jogo da qual recolhe todas as sementes. Na sequência vai depositando-as uma a uma nas cavas adjacentes, sempre no sentido anti-horário, percorrendo as cavas do campo adversário quando necessário (mas sem poder passar pelo oásis dele), isto é, numa trajetória circular. A cada passada pelo seu oásis, deposita uma semente.

A última semente depositada determina vantagens particulares importantes: $1^{\circ} \mathrm{se}$ esta recair no seu oásis, permitirá nova jogada; $2^{\circ}$ se recair sob uma cava vazia no seu próprio lado, permitirá recolher para o seu oásis todas as sementes da cava adjacente do adversário (cava em frente), inclusive a sua própria semente depositada. Por estas regras, torna-se evidente que cada jogador deve efetuar cálculos mentais para a escolha da melhor jogada, seja para colheita de maior quantidade de sementes, seja para 
impedimento do adversário fazê-lo, o que faz com que o jogo se torne uma disputa de estratégias apoiadas em conceitos matemáticos.

O jogo avança com as sementes disponíveis para movimento diminuindo em quantidade na medida em que vão sendo recolhidas aos oásis de cada jogador. Caso algum jogador ficar sem sementes no seu campo de jogo, e havendo possibilidade, o adversário obriga-se a jogar transferindo sementes para seu lado. $\mathrm{O}$ jogo encerra-se quando não há mais sementes num dos lados nem possibilidades de transferi-las; as sementes restantes são recolhidas ao oásis respectivo. Vencerá a partida aquele jogador com a maior quantidade de sementes em seu oásis.

Pereira (2011) analisa que a prática envolvendo o jogo Mancala, além de desenvolver fundamentos matemáticos, reforça a auto-estima do aluno na medida em que reconhece na sua ancestralidade o conhecimento matemático necessário para a elaboração do jogo e para a construção de boas jogadas.

D’Ambrósio (2005) destaca que a utilização dos elementos culturais próprios de cada sociedade, objetos materiais ou imateriais que a constituem e que se moldam ao modo de ser e de entender o seu mundo, são estratégias que o educador deve valer-se no objetivo de promover o desenvolvimento de seus educandos. São esses saberes que constituem a identidade de seu grupo humano, e fundamentais para sua sobrevivência e transcendência.

\section{OS VALORES CIVILIZATÓRIOS AFRO-BRASILEIROS E A ETNOMATEMÁTICA}

Um exemplo de ação que converge para o objetivo de redução das diferenças sofridas por jovens negros é o projeto educativo "A Cor da Cultura", de valorização da cultura afro-brasileira e resultado de iniciativas entre o Canal Futura, a Petrobrás, o Centro de Informação e Documentação do Artista Negro - CIDAN, a Fundação Palmares, a TV Globo, a Secretaria de Políticas de Promoção da Igualdade RacialSEPPIR, e o Ministério de Educação e Cultura - MEC. Entre seus objetivos estão a criação de materiais audiovisuais sobre história e cultura afro-brasileiras, a valorização de iniciativas de inclusão dando visibilidade à ações afirmativas já promovidas pela sociedade e a criação de práticas pedagógicas inclusivas. 
O projeto "A Cor da Cultura" tem dois grandes componentes: a produção audiovisual e a formação de professores. Este segundo componente incluiu a produção de um kit educativo e ações de capacitação para quatro mil professores para sua utilização em sala de aula. Dentre esses recursos encontra-se o Mapa de Valores Civilizatórios, gravura que interconecta conceitos atribuídos às populações de origem africana (figura 3), porque identificáveis nas suas tradições. São elementos culturais sempre presentes, ou recorrentemente percebidos como típicos dos povos afrobrasileiros. Isto é, embora haja diversidade de organização dos povos africanos, de suas línguas, de costumes, de ritos, etc, é possível verificar uma convergência de identidades nas suas manifestações culturais. Para Brandão (2006, p. 17), "tais valores não são lineares, estanques, mas se interpenetram, se hibridizam, obedecem a fluxos e conexões que se dão na cotidianidade e na imersão e absorção dessa dimensão civilizatória".

Diversos autores listam valores civilizatórios em sintonia com os expressos nesse programa, eventualmente divergindo num ou noutro ponto específico. Leite (1995) reconhece a Força Vital, a Palavra (oralidade), o Homem (corporeidade e religiosidade), a Socialidade (cooperativismo), e Ancestralidade, além de outras, como características uniformes observáveis em sociedades da África Ocidental, essencialmente agrárias mas com distinta organização política.

Importante reconhecer que a cultura de um povo está relacionada fortemente com os desafios e as soluções que encontra para sobreviver e prosperar como sociedade, portanto altamente dinâmica e dependente das relações sociais presentes em seus lugares de vida. Para tanto, o sentido de cultura está apoiada na ideia de Stuart Hall (2018). Para o referido autor, cultura não é somente uma prática ou a soma descritiva de hábitos e costumes, ela é atravessada por todas as práticas sociais e seus interrelacionamentos, sendo reveladoras de si mesmas dentro de identidades (HALL, 2018).

Nesse sentido, a população negra que chegou no Brasil carregada de uma bagagem cultural relativamente heterogênea, considerando a diversidade de origens no continente africano, se adapta a realidades diversas e estão envolvidas em diversas práticas sociais. Por isso, um dos propósitos desse trabalho é compreender as interrelações de práticas vividas e experimentadas numa comunidade quilombola. A presença da população negra em nosso país constitui a base cultural (inter-relações de práticas sociais trazidas do continente africana e adaptadas ao território brasileiro), 
posicionando seus saberes e conhecimentos técnicos na força civilizatória que constitui essa nação.

Os saberes, que representam os conhecimentos historicamente produzidos estão representados na matriz dos valores civilizatórios proposto por Azoilda Trintade (2010). Conforme Trindade (2010), valores correspondem aos fundamentos morais, éticos e comportamentais historicamente vivenciados e construídos e civilização, o conjunto de produções materiais e imateriais de uma sociedade. Portanto, a autora, a partir do mapa dos valores civilizatórios afro-brasileiros, permite reconhecer a afro-brasilidade ressignificada pelas matrizes africanas. A população de matriz africana recria em território brasileiro um conjunto de práticas, de crenças, de valores que mesclaram com aqueles conhecimentos trazidos de suas terras, inseridos num novo espaço, num outro regime econômico, num novo ambiente social, estabelecendo uma cultura particular afro-brasileira, mas carregada dos matizes ancestrais oriundos do continente africano. A figura 3 representa os valores civilizatórios afro-brasileiros.

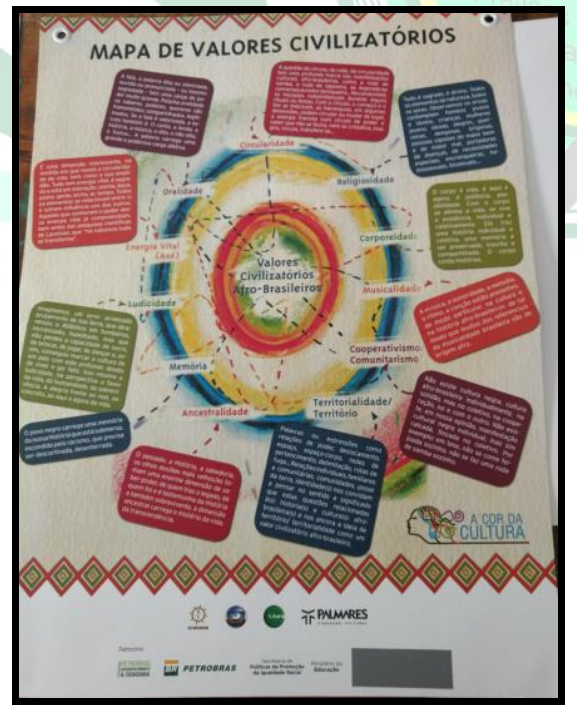

Figura 3 - Mapa de Valores Civilizatórios

Fonte - A cor da cultura

Através do reconhecimento dessa identidade com os povos africanos, a valorização de tais aspectos presentes nos seus saberes e fazeres tradicionais podem contribuir na desconstrução do imaginário depreciativo que está presente nas manifestações de racismo, substituindo-o pelo orgulho do passado e pelo amor próprio 
que decorre de uma autoestima valorizada. Ampliando ainda mais essa discussão, Homi Bhabha (2007) também auxilia na percepção dos modos de ver e sentir os valores civilizatórios afro-brasileiros numa comunidade quilombola porque nestes espaços a formação de identidades são ressignificadas reportando a necessidade de olhar além dos aspectos originais da cultura e observar as interações que se estabelecem, ou seja, que novos signos de identidade e estruturas inovadoras/colaborativas e até mesmo de contestação estão presentes. Essa ideia torna-se importante para compreender como a comunidade reconhece os valores civilizatórios afro-brasileiros no seu contexto comunitário.

Trazer à tona o debate sobre estes valores oportuniza ainda a adoção de elementos próprios das comunidades, seus fazeres, como objetos pedagógicos. Ubiratan D’Ambrosio (2005, p.112) assinala que:

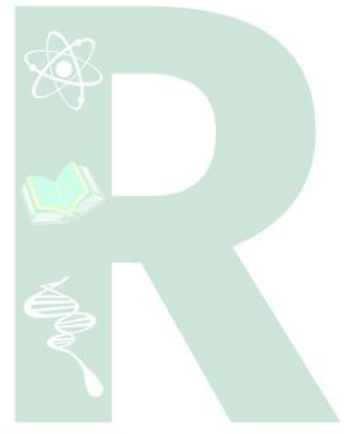

... o homem (espécie Homo sapiens sapiens), bem como as demais espécies que a precederam, os vários hominídeos reconhecidos desde há 5 milhões de anos antes do presente, têm seu comportamento alimentado pela aquisição de conhecimento, de fazer(es) e de saber(es) que lhes permitiram sobreviver e transcender, através de maneiras, de modos, de técnicas, de artes (techné ou "ticas") de explicar, de conhecer, de entender, de lidar com, de conviver com (mátema) a realidade natural e sociocultural (etno) na qual ele, homem, está inserido. Ao utilizar, num verdadeiro abuso etimológico, as raízes "tica", "matema" e "etno", dei origem à minha conceituação de Etnomatemática.

Os fundamentos da Matemática se distinguem da Etnomatemática na medida em que a primeira apoia-se num sentido generalista e universal, enquanto que a segunda busca a especificidade e o caráter local, reconhecendo que tradição, sociedade e cultura são formas de produção do conhecimento importantes e necessárias. Ao formular as bases para o conceito da Etnomatemática, D’Ambrosio considera a importância da utilização dos saberes comunitários, de forma que estejam presentes nas relações educador/educando, fazendo emergir um debate que se apoia em valores locais para alcançar significados transcendentais.

A Etnomatemática propicia um diálogo entre a Matemática acadêmica e universal com as ideias das culturas locais, por um lado ampliando a aplicação daquele conhecimento em diversas situações cotidianas das comunidades, e de outro dando-lhe novos significados e sentidos. Mas a Etnomatemática também se funda na ideologia por detrás dos discursos. Segundo D’Ambrosio (2005, p. 114) 
...Os grandes heróis da matemática, isto é, aqueles indivíduos historicamente apontados como responsáveis pelo avanço e consolidação dessa ciência, são identificados na Antigüidade grega e posteriormente, na Idade Moderna, nos países centrais da Europa, sobretudo Inglaterra, França, Itália, Alemanha. Os nomes mais lembrados são Tales, Pitágoras, Euclides, Descartes, Galileu, Newton, Leibniz, Hilbert, Einstein, Hawkings. São idéias e homens originários do Norte do Mediterrâneo. Portanto, falar dessa matemática em ambientes culturais diversificados, sobretudo em se tratando de indígenas ou afro-americanos ou outros não-europeus, de trabalhadores oprimidos e de classes marginalizadas, além de trazer a lembrança do conquistador, do escravista, enfim do dominador, também se refere a uma forma de conhecimento que foi construído pelo dominador, e da qual ele se serviu e se serve para exercer seu domínio.

A ideologia implícita nos currículos tradicionais do ensino de Matemática reforça continuamente que há uma superioridade do conhecimento de inspiração e estruturação inteiramente Européia, uma supremacia que desloca para lados opostos este conhecimento dos demais, o que justificaria esta dominação.

O programa lançado por D’Ambrósio possui convergência absoluta com os ensinamentos de Paulo Freire quando este afirma que a história do mundo não é uma narrativa acabada, conclusa. Todos em particular, e os educadores de uma forma especial, têm a possibilidade de moldar suas histórias pessoais e daqueles que os cercam a partir de suas ações. Com a afirmação "O mundo não é. O mundo está sendo." (FREIRE, 1996) instiga-nos a não sermos apenas objetos da história, mas seus sujeitos, capazes de interferir no futuro, transformando-nos de simples expectadores da realidade em sujeitos comprometidos com uma nova condição social e política que se opõe às desigualdades de nossa sociedade. Ensina Freire (1996, p.42):

Como educador preciso de ir "lendo" cada vez melhor a leitura do mundo que os grupos populares com quem trabalho fazem de seu contexto imediato e do maior de que o seu é parte. O que quero dizer é o seguinte: não posso de maneira alguma, nas minhas relações políticopedagógicas com os grupos populares, desconsiderar seu saber de experiência feito. Sua explicação do mundo de que faz parte a compreensão de sua própria presença no mundo. E isso tudo vem explicitado ou sugerido ou escondido no que chamo "leitura do mundo" que precede sempre a "leitura da palavra".

Se, de um lado, não posso me adaptar ou me "converter" ao saber ingênuo dos grupos populares, de outro, não posso, se realmente progressista, impôrlhes arrogantemente o meu saber como o verdadeiro.

Temos nesta citação reafirmado o respeito que deve ser observado pelos saberes populares, e de como os mesmos devem estar presentes no diálogo entre educador e educando. A "leitura" refere-se à necessidade de conhecer o ambiente na qual o 
educando está inserido, valorizando a experiência cotidiana e o saber fazer, próprio de sua cultura e de sua realidade. $\mathrm{O}$ educador que pretende ser progressista na concepção de Freire, é sensível à esta leitura, provocando o educando para uma nova forma de compreensão do seu contexto. Compreensão que deixe claro a inculcação de culpa das próprias pessoas pela situação em que vivem, desviando das classes dominantes e do poder ideológico que manipulam qualquer responsabilidade pelas condições precarizadas que lhes são oferecidas.

\section{O PERCURSO DA PESQUISA}

Foi realizado um longo percurso para a efetivação desta pesquisa, sendo importante para construir com a comunidade a relação de confiança necessária para o seu desenvolvimento, pois a mesma não conhece a princípio o pesquisador e seus objetivos.

A Mancala é um dos jogos do acervo do grupo de pesquisa MathemaTIC ${ }^{1}$, projeto coordenado por um dos autores deste artigo e com a participação do autor principal. Em uma das ações do grupo, a partir do convite realizado, trabalhamos com jogos na Comunidade Kilombola Morada da Paz no município de Triunfo no segundo semestre de 2017. A comunidade desenvolve anualmente o Ipadê da Juventude e a Colônia de Férias Curumim-Omadê, ocasião em que reúne crianças e jovens através de atividades integradoras.

No primeiro semestre de 2018 foi cursada a disciplina Encontro de Saberes pelo pesquisador principal, cuja ementa trata da interculturalidade, diversidade cultural, pluralidade epistêmica e docência com mestres dos saberes tradicionais e populares, além da criação de projetos colaborativos e de ações de intervenção social. Dentre os demais mestres presentes na disciplina, participaram Rosângela da Silva Ellias (Janja) e Karina Rejane da Silva Ellias, ambas lideranças do Quilombo dos Alpes. Essa participação propiciou conhecer o Quilombo dos Alpes e suas lideranças. A disciplina

${ }^{1} \mathrm{O}$ projeto, sob orientação da Prof. Dra. Leandra Anversa Fioreze, objetiva refletir sobre a ação pedagógica do Educador Matemático com vistas a construção de alternativas metodológicas para o processo de ensino e aprendizagem da Matemática na Educação Básica,sendo um de seus subprojetos o estudo das contribuições de determinados jogos na construção do pensamento matemático. 
previa a elaboração de um projeto de prática aplicada a uma comunidade. Junto com os colegas da disciplina, elaboramos em conjunto de ações que reunia a valorização das trilhas existentes no Quilombo dos Alpes com oficina de jogos, sendo um deles a Mancala.

No segundo semestre de 2018 o pesquisador principal se inseriu no Núcleo de Estudos de Geografia e Ambiente - NEGA, coordenado por Claudia Luísa Zeferino Pires. No Núcleo desenvolve-se um programa de extensão do Departamento de Geografia da UFRGS voltado às comunidades quilombolas urbanas de Porto Alegre, dentre elas o Quilombo dos Alpes. Dentre seus diversos objetivos, busca discutir e propor diferentes abordagens e estratégias metodológicas no que tange a ação política e práticas emancipatórias ${ }^{2}$. Esta inserção no grupo permitiu incluir a oficina Mancala ao calendário de ações voltadas a comunidade quilombola dos Alpes no segundo semestre de 2018. As oficinas foram realizadas ao longo desse período e construídas em etapas. No planejamento, iniciou-se a leitura de alguns textos por todo o grupo, sobre os quais discutimos teoricamente a respeito de questões que fundamentaram nosso conhecimento para a lida com as práticas educativas especialmente voltadas para educação quilombola.

Nesse sentido, a presença em outras iniciativas do coletivo no Quilombo objetivou estabelecer uma relação horizontal com a comunidade. Exemplo disso se demonstra na implantação de horta comunitária (uma das práticas educativas), quando o coletivo de integrantes do NEGA juntamente com a comunidade e servidores municipais vinculados à Secretaria do Meio Ambiente iniciaram a implantação de um quintal de hortaliças para os moradores no entorno da Sede da Associação (figura 4).

\footnotetext{
${ }^{2}$ https://www.ufrgs.br/nega/sobre-o-nega/
} 


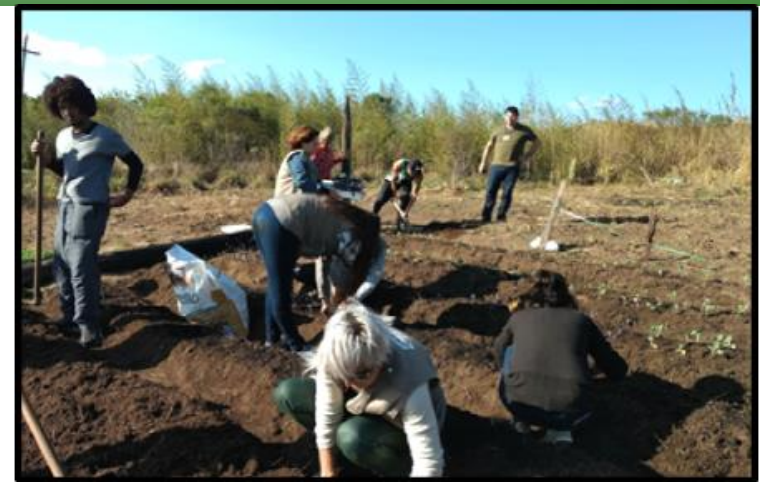

Figura 4 - Implantação de horta comunitária no Quilombo dos Alpes. Fonte- NEGA - Núcleo de Estudos de Geografia e Ambiente

Através de suas lideranças, o Quilombo dos Alpes articula-se com outras comunidades quilombolas e instituições da sociedade, tal qual a UFRGS, buscando alternativas para alcançar direitos que em geral não são disponibilizados de maneira imediata: o acesso a políticas públicas em favor da comunidade, para ser alcançado, requer tensionamento e pressão popular.

Afirmar-se como quilombola é acima de tudo uma ação política. Para concretizarse como comunidade quilombola, sua organização e manutenção prescindem de lideranças capazes de manter a mobilização de todos em torno dos grandes objetivos que se norteiam pela preservação de seu patrimônio físico e cultural. Por essa razão qualquer aproximação a essas comunidades exige uma atitude de respeito e de atendimento às conveniências da mesma, entendendo que cada comunidade tem distintas necessidades e interesses particulares.

\section{METODOLOGIA DA PESQUISA}

Os sujeitos da pesquisa são exclusivamente crianças e jovens pertencentes à comunidade selecionada, participantes do cotidiano das famílias autodeclaradas quilombolas, capazes de refletir os saberes e fazeres incorporados pelo pertencimento àquele ambiente.

Para desenvolver esta pesquisa foi planejada uma oficina na comunidade quilombola, com o intuito de que os jovens, ao jogar Mancala, se envolvam na discussão sobre os valores civilizatórios descritos no kit A Cor da Cultura, e registrem 
como eles percebem a manifestação dos mesmos durante o jogo. Os registros, além das anotações em caderno de campo, foram confrontados com as filmagens obtidas durante a dinâmica, além de fotografias, de modo a propiciar o cruzamento dos dados.

A busca da resposta à pergunta diretriz nos encaminhou a uma investigação qualitativa do tipo pesquisa participante. Segundo Brandão, Borges (2007, p. 52),

\begin{abstract}
O compromisso social, político e ideológico do(a) investigador(a) é com a comunidade, com as suas causas sociais. $\mathrm{Na}$ maior parte dos casos, a pesquisa participante é um momento de trabalhos de educação popular realizados junto com e a serviço de comunidades, grupos e movimentos sociais, em geral, populares. Na pesquisa participante, sempre importa conhecer para formar pessoas motivadas a transformarem os cenários sociais de suas próprias vidas e destinos.
\end{abstract}

Nessa investigação objetivou-se atuar de forma horizontal e comprometida social e politicamente em favor das causas que a comunidade defende. $\mathrm{O}$ compromisso social e político dos pesquisadores devem ser com a comunidade, com as pessoas e grupos envolvidos, com suas causas sociais. E o resultado da mesma deve servir à comunidade, contribuir para sua emancipação, ser apropriado por todos que estejam envolvidos. A pesquisa deve transformar-se numa oportunidade de fortalecer valores culturais, a sabedoria, o conhecimento e as raízes herdadas da ancestralidade negra, principalmente no espaço escolar.

A relação de horizontalidade buscada entre pesquisadores e a comunidade se alcança quando este atende demandas de interesses dela, o que resulta numa demonstração da valorização dos saberes que a comunidade detém, do reconhecimento que estes valores se equiparam a de qualquer outra coletividade e de sua capacidade de compreender e transformar o mundo que o cerca. A utilização do jogo Mancala, ao se mesclar com os valores civilizatórios afro-brasileiros presentes na comunidade, pode produzir o resgate de uma tradição lúdica e reforçar a autoestima e o auto-respeito dos participantes.

Para concretização da oficina foram construídos dez tabuleiros de Mancala utilizando materiais duráveis (tabuas de madeira coladas sob painéis laminados) e com bom acabamento, de modo a valorizar a ação e servir de atrativo adicional ao jogo. Os tabuleiros foram dimensionados para utilização com sementes coletadas no próprio 
quilombo, com grãos como feijão e milho, e doados à comunidade, juntamente com um impresso descritivo das suas regras. Com isso se espera que a comunidade amplie e divulgue o interesse pelo jogo, disponibilizando na sua sede os tabuleiros e a cartela contendo as regras para servir como uma ferramenta de resgate do jogo. A disseminação do mesmo, de sua história e de seus vínculos com a tradição e história ancestral objetiva desenvolver a autoestima e o reconhecimento da dimensão e importância dos saberes advindos do continente africano na bagagem cultural dos povos afrodescendentes.

A oficina se realizou na sede da Associação dos Moradores do Quilombo dos Alpes, construída pela própria comunidade e conhecida como Octógono em razão de sua forma de poliedro de oito faces e por representar arena de lutas. No local, além da equipe do NEGA, também se encontravam Rosângela, a Janja, e outros membros da comunidade, além de oito jovens entre doze e quinze anos convidados para a dinâmica, que são referidos com a designação alfabética $(A, B, C, \ldots)$ para preservação de suas identidades.

Os materiais levados para a oficina foram nove tabuleiros de madeira, um tabuleiro maior, mapa da África e mapa Valores Civilizatórios, ambos do kit A Cor da Cultura, e dez pequenas bandeiras de cartolina com cada um dos valores civilizatórios apresentados no mapa Valores Civilizatórios. O tabuleiro maior referido constituiu-se de doze pequenos vasos plásticos (aproximadamente $10 \mathrm{~cm}$ de altura e diâmetro) presos a uma base plana e rígida além de dois um pouco maiores à guisa dos oásis, para serem utilizados com as sementes de "olho de boi", que são facilmente encontradas no território do quilombo, e que possuem grande valor espiritual na tradição afrobrasileira.Este tabuleiro maior foi construído pela equipe do NEGA para ser utilizado na demonstração das regras do jogo.

\section{A REALIZAÇÃO DA OFICINA}

Após uma rápida apresentação pessoal entre todos, deu-se início à oficina, primeiramente introduzida pela professora Claudia Luísa Zeferino Pires que apresentou a Mancala como um jogo com origem na África e relacionou com a geografia do continente africano e seus valores civilizatórios. Importante destacar que o Mapa 
Valores Civilizatórios é recorrentemente trabalhado na comunidade, porque se constitui em referencial pedagógico já utilizado pelo NEGA.

Ao explicitar as regras da Mancala o pesquisador principal referiu-se a matemática presente no jogo, na determinação da jogada mais produtiva e na construção do pensamento lógico: "Uma vez que o jogo começa com quatro sementes em cada cava, considerando que são 12 cavas, qual a quantidade de sementes necessárias para iniciar o jogo?" foi a pergunta inicial lançada para exemplificar o estreito relacionamento entre o ato de jogar e o pensamento matemático aplicado ao mesmo.

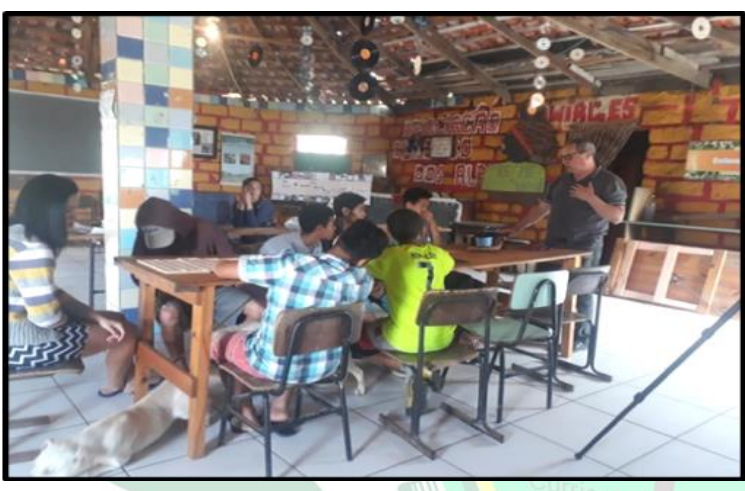

Figura 5 - Apresentação das regras da Mancala.

Fonte - NEGA - Núcleo de Estudos de Geografia e Ambiente

Salientou-se que a cada jogada é necessário que se contem as sementes a fim de determinar a posição da última semente, se verifique a melhor opção de jogada entre (em geral) as seis possibilidades de escolha, seja para construir uma estratégia de captura de sementes vantajosa, seja para bloquear jogada do adversário.

Quantas sementes são necessárias para o jogo? Qual a quantidade mínima de sementes para vencer? É preciso que se conte as sementes dos dois jogadores para saber quem venceu? Não basta contar de apenas um? Porque é necessário contar a quantidade de sementes da cava que se escolhe para jogar? Foram perguntas lançadas entre os jovens, na medida em que a oficina se desenrolava. A intenção das mesmas era demonstrar como os fundamentos matemáticos são importantes para compreensão do jogo e para a elaboração da estratégia do jogador.

Os jovens jogaram em duplas, aperfeiçoando o entendimento das regras e experimentando diversas estratégias de jogo. Rapidamente todos estavam envolvidos com suas jogadas, iniciando nova partida assim que concluíam um jogo. Por vezes 
mudavam de duplas, ou se agrupavam para jogar discutindo as possibilidades. Os presentes tiveram tanto interesse que mesmo os adultos na assistência aos poucos iam se interessando e participando das jogadas.

Em aproximadamente oitenta minutos de duração da etapa de jogos, várias partidas foram disputadas, e alguns ainda insistiam em permanecer jogando quando todos foram convidados para seguirmos à última etapa da prática educativa: a discussão sobre os valores civilizatórios identificados no jogo.

Com recortes de cartolina de tamanho aproximado a uma folha de ofício sustentada por uma vareta, cada recorte referindo um dos valores civilizatórios apresentados no mapa do kit A Cor da Cultura, foram apresentadas as dez expressões: oralidade, musicalidade, memória, ancestralidade, cooperativismo, corporeidade, energia vital, ludicidade, circularidade e religiosidade. Dispostos sobre a mesa sem nenhuma ordem predefinida, jovens e crianças foram convidados a escolher algum dos valores civilizatórios, e referir como ou onde esse valor se apresenta ou se expressa na prática do jogo Mancala, estimulando a reflexão coletiva e a expressão verbal deles. A dinâmica durou cerca de 20 minutos e permitiu referir os dez cartazes preparados para a prática, alguns com maior participação, outros com menor compreensão. Objetivou-se proporcionar a participação de todos os jovens, embora alguns apresentassem comportamento introvertido ou tímido.

\section{ANÁLISE}

As falas dos jovens durante a etapa de reflexão sobre os valores civilizatórios presentes na Mancala foram integralmente captadas em imagens de vídeo pela equipe do NEGA, o que permitiu uma descrição fidedigna das mesmas, corroborando as anotações do caderno de campo. O grupo pequeno e em certa medida constrangido precisou ser estimulado para expressar-se; o acanhamento é mais uma demonstração dos efeitos do racismo sofrido no cotidiano daqueles jovens. Alguns preferiram não falar sobre a prática, e isto foi respeitado. Aqueles que se manifestaram, fizeram com moderação, mas foi sensível em seus olhares e nas suas falas o interesse com que acompanhavam a tudo que ocorria, ao que era dito. 
Segue na ordem que foi citada pelos jovens, as manifestações apresentadas em itálico, comentários expressos na realização da oficina e reflexões sobre as manifestações da oficina desenvolvida. Devido ao espaço disponível neste artigo, não serão apresentados na íntegra o conteúdo de alguns dos valores civilizatórios:

a) Cooperativismo: Para iniciar com um exemplo foi escolhida a palavra

Cooperativismo e questionou-se os jovens se a cooperação se manifestava na atividade recém finalizada. O jovem A citou que "cooperativismo acontece quando uma pessoa ajuda a outra para escolher uma jogada". De fato, durante os jogos aconteceram diversos momentos em que um jogador recebia ajuda para escolher uma boa jogada. Às vezes a ajuda vinha do companheiro quando jogavam entre as duplas, às vezes de um terceiro assistente, talvez mesmo do jogador adversário. Estas situações são exemplos de cooperativismo, que é um comportamento observado especialmente em comunidades carentes, quando o pouco que se tem é compartilhado. As pessoas voluntariamente gostam de contribuir umas com as outras, especialmente para a solução de algum problema, e no caso do jogo a ajuda se manifestava como uma sugestão de jogada. Temos na fala do jovem A um exemplo de cooperativismo percebido, dentre diversos outros exemplos.

O ato de jogar por si só é um ato cooperativo, pois participar voluntariamente de um jogo, qualquer que seja, significa reconhecer as regras e o adversário, compartilhar o espaço e os materiais com que se constitui o jogo, submeter-se a uma arbitragem comum. Cooperar é, no dicionário Global escolar (2007), operar em conjunto, ajudar, operar simultaneamente. Jogar também é operar em conjunto. Então jogar de fato é um ato de cooperação.

b) Memória

c) Oralidade: O jovem B escolheu a palavra Oralidade referindo que ela está presente "quando o jogador fala a jogada que fará". De fato, uma das diversões da Mancala é que, embora não necessário, é usual que se comente a jogada que se faz, seja contando a cada semente posta, seja antecipando onde a última semente será depositada ou ainda uma eventual vantagem conquistada. Quando os jovens formaram duplas, cada um deles discutia as possibilidades de jogada. A fala também esteve presente na etapa de aprendizagem do jogo, pois a exposição das regras ocorreu de forma oral, assim como 
se espera que os jovens retransmitam para outros interessados seu aprendizado da Mancala.

A falta da linguagem escrita entre a maioria dos povos africanos tornou a oralidade um recurso fundamental, assim como a memória, para preservação dos saberes e fazeres dos povos africanos. Conforme Nascimento e Ramos (2013), a valorização da tradição oral na África demonstra um modo de preservar a sabedoria da ancestralidade, além da função de comunicação.

d) Corporeidade

e) Religiosidade: $\mathrm{O}$ jovem $\mathrm{D}$ selecionou a palavra Religiosidade acrescentando "Religião Africana", apontando para o espaço do salão onde se reverenciam os símbolos de divindades africanas, certamente reconhecendo a presença dos elementos religiosos no jogo. Ao serem questionados sobre quais elementos da Mancala eram considerados sagrados à tradição africana, os jovens responderam "as sementes". Convidada a se manifestar sobre o caráter sagrado das sementes, Janja disse que as mesmas são sagradas porque são utilizadas de diversas formas nas cerimônias religiosas, nos patuás como oferenda aos Orixás ou nos próprios domicílios para "trazer energia e coisas boas para a casa da gente". Segundo Janja, "as sementes são sagradas em todas as religiões africanas". Evidência marcante da importância do valor da religiosidade é a existência dentro da edificação de um espaço de celebração com diversos elementos que compõe as divindades reconhecidas por sua religião, que convivem com os afazeres cotidianos de todos que circulam na sede da Associação, local de convivência cotidiana entre as pessoas e seus objetos de reverência espiritual.

f) Ancestralidade: A palavra Ancestralidade foi selecionada pelo jovem D. Quando perguntado sobre o significado da palavra, aponta para o espaço para a prática da religião com a representação do preto-velho, referindo-o como "exemplo de ancestralidade”. Ancestral para os quilombolas é aquilo que veio da África, como a religião, e como a Mancala, que veio da África há muitas e muitas gerações atrás. Percebe-se como os valores civilizatórios estão interconectados: Ancestralidade, Memória e Religiosidade aparecem engendrados nesse exercício de relacionar características culturais representados na Mancala. Outra manifestação deste valor se percebe no respeito dedicado aos mais velhos, àqueles que nos antecedem. É intenso o respeito que os jovens dedicam à Janja, que é avó de todos eles. O respeito é percebido no olhar e na fala de todos eles ao se dirigirem à avó, ou quando ela fala e todos 
demonstram atenção às suas palavras. Ancestral também é a agricultura, o sustento da família através do plantio e colheita das sementes de cereais, vegetais, frutas e verduras que fazem parte do legado de cada povo que veio da África.

g) Energia Vital: O jovem A explicou que "é preciso energia para jogar”. De fato, é necessária energia para jogar, assim como para viver. Aqui energia no sentido de entusiasmo, de força e de harmonia, de vontade de viver. Sinônimo de Energia Vital é Axé, palavra de origem africana utilizada para referir esta força que deve ser "constantemente renovada e potencializada, para que haja harmonia entre o corpo e o meio, tanto terreno como espiritual" (ALVES, 2016, p. 18). A alegria obtida com o ato de jogar, de conversar, de se divertir e sorrir em conjunto presente naquele momento de realização da intervenção na sede do Quilombo dos Alpes é uma demonstração de Axé, de Energia Vital. Essa energia também esteve presente quando da confecção dos tabuleiros que foram construídos especialmente para a comunidade, na coleta das sementes que antecedeu a prática realizada, na discussão e planejamento conjunto da intervenção, pois todas foram etapas cumpridas com alegria e em harmonia entre todos.

h) Ludicidade e i) Circularidade

j) Musicalidade: A última bandeira sobre a mesa com a palavra Musicalidade foi representada pelos jovens A e D com o ritmo das sementes caindo sobre as cavas. $\mathrm{O}$ som da batida das sementes contra o tabuleiro, e o ritmo entre cada batida são exemplos perfeitos da música de origem africana, essencialmente de percussão. A batucada é característica marcante de todos os ritmos africanos (dos brasileiros também, como a reafirmar nossa origem), e qualquer sequencia harmônica de batidas já se transforma num convite para outros acompanhamentos. Caixa de fósforos transforma-se em instrumento musical capaz de arrastar uma bateria de escola de samba. O samba é uma criação genuinamente afro-brasileira, de sucesso internacional e um dos ritmos africanos, dentre tantos outros. Outra conexão entre a Mancala e esse valor civilizatório se obtém com as sementes, que também são utilizadas em diversos instrumentos musicais de origem africana; chocalhos, maracas, xequerês e caxixis. O jovem A com uma semente olho-de-boi começa uma batucada contra o tampo da mesa, como se já desejasse que todos o seguissem no ritmo.

\subsection{DIÁLOGO COM AUTORES REFERENCIAIS}


O planejamento da pesquisa considerou a necessidade de que a mesma fosse dialogada, respeitando o espaço e os saberes próprios e particulares da comunidade, afetiva com os jovens no sentido de ultrapassar barreiras de comunicação, e crítica ao reconhecer a presença da discriminação aos negros em nossa sociedade. Confrontando as observações colhidas na intervenção e as reflexões decorrentes dos diálogos tidos com a comunidade, suas lideranças e jovens educandos, revisitamos ideias de educadores comprometidos com uma educação igualitária, libertadora, que promova a diminuição das desigualdades sociais e a emancipação humana.

Paulo Freire (1996) afirma que ensinar exige respeito aos saberes socialmente construídos na prática comunitária, sobretudo os das classes populares, e o dever de discutir a razão de ser de alguns desses saberes em relação com o ensino dos conteúdos. O resgate da prática da Mancala e a discussão dos valores civilizatórios tornam-se uma oportunidade de explorar o respeito aos educandos e a intenção de contribuir, afetivamente e socialmente, na caminhada que cada um perseguirá.

Freire (1996) reafirma a necessidade de um posicionamento político do educador/pesquisador quando se envolve com seus educandos. Somente com o engajamento, com a compreensão da realidade vivida pela comunidade, das desvantagens impostas por sua condição social e econômica, da discriminação sofrida e das consequências de uma educação mal atendida, pode o educador de fato posicionarse como indutor de uma formação transformadora, em que o educando reconheça sua realidade e torne-se capaz de modificá-la em favor de sua comunidade.

$\mathrm{O}$ respeito se expressa especialmente quando o educador assume uma posição horizontal frente ao educando. Nessa condição, ainda que o primeiro detenha informações desconhecidas pelo segundo, isso não deve produzir sentimento de supremacia ou de poder; o conhecimento que o segundo possui nunca é nulo ou inexistente, e suas experiências pessoais podem contribuir para a apreensão dessa nova informação, de modo que o mesmo passe a constituir-se como seu acervo pessoal.

Os saberes que os jovens adquirem no ambiente familiar, na comunidade, trazidos nas histórias de seus avós, herdados de seu modo de viver e compreender o mundo, de sua tradição e ancestralidade, podem e precisam ser explorados pelo educador. É sobre esses antigos saberes que os novos podem ou não ser incorporados, de maneira reflexiva, dando-lhe outros sentidos. 
Seguindo essa mesma compreensão, D`Ambrósio (2005, p. 112) assinala que indivíduos e povos têm, no decorrer da história e em suas existências, "criado e desenvolvido instrumentos de reflexão, de observação, instrumentos teóricos", desenvolvendo técnicas e habilidades que lhe permitem sobreviver, conhecer, aprender e transcender, em diferentes ambientes, naturais,sociais e culturais. Nessa passagem D’Ambrósio poderia estar se referindo explicitamente aos povos africanos, pois resume exatamente a jornada humana, sua origem no continente africano de onde saiu para tornar-se o ser dominante do planeta inteiro, no qual sobreviveu e transcendeu (HARARI, 2018). Acoberta-se muito o conhecimento produzido pelos povos africanos (e indígenas, ou de outras origens que não a tradicional europeia), ou ainda, o mesmo é tratado de forma pitoresca ou pueril, preconceituosamente.

Falar e valer-se de instrumentos, de materiais, de saberes tradicionais desses povos é dar-lhes visibilidade, reconhecer sua importância na nossa jornada, creditá-los como essenciais na formação de nossa cultura global e do nosso saber contemporâneo. Com essa compreensão, a Etnomatemática apresenta-se como uma possibilidade concreta de contribuir para o combate ao preconceito relacionado às diferenças de cultura presentes em nossa sociedade.

É necessário registrar que uma ação nunca se encerra em si mesmo: a repercussão sobre seus sujeitos e os desdobramentos decorrentes, em geral, acabam por influenciar a vida daqueles que foram tocados pela mesma. Mesmo que as ações da pesquisa sejam locais e parciais, e incidem sobre apenas um aspecto de toda uma vida social, não se perde de vista as integrações e interações que compõe o todo (BRANDÃO; BORGES, 2007).

O resgate dos saberes associados às nossas origens, à nossa história de vida, é importante. O que meus avós, e também os avós dos meus avós realizaram, permanecem em mim e me configuram como pessoa. Quanto maior meu conhecimento a respeito desse passado, de suas práticas, de suas convicções, de suas compreensões do mundo, maior será meu autoconhecimento, meu amor e respeito próprio, minha capacidade de me compreender e compreender o mundo. E com isso transformar a mim mesmo e a vida que me cerca em busca de meus objetivos de vida. O resgate da Mancala e dos valores civilizatórios africanos convergem nesse sentido. 


\section{CONSIDERAÇÕES FINAIS}

Da análise da questão da pesquisa: como o jogo Mancala pode ser utilizado como recurso pedagógico para instigar a reflexão sobre os valores civilizatórios afrobrasileiros,conclui-se que a Mancala pode ser utilizada associada à apresentação dos valores civilizatórios da população negra,com o propósito de valorizar e de reconhecer a importância de seus saberes e fazeres. No experimento os jovens encontraram as conexões entre a Mancala e todos os valores civilizatórios, atentos e interessados nos acontecimentos. O resgate do jogo Mancala em comunidade quilombola permitiu tratar da riqueza e diversidade cultural dos povos africanos, resgatar saberes e fazeres virtuosos, que objetivam contribuir para aumentar a autoestima e empoderamento dos jovens, ao mesmo tempo que serviu de mote para introdução de conceitos matemáticos que estão presentes nos currículos do ensino fundamental e médio.

Incorporar os valores civilizatórios afro-brasileiros na prática pedagógica, qualquer que seja a disciplina utilizada, dá visibilidade a características culturais positivas e pode auxiliar para elevar a autoestima de jovens em fase de afirmação própria. Tratar disso na aula de matemática é ainda mais positivo, já que a maior parte do currículo escolar da escola básica ignora a contribuição africana na construção de nossa cultura. Além disso, há escassez de materiais didáticos que mostrem as contribuições tecnológicas e científicas dos africanos na Matemática (SANTOS, 2018).

Enfim, reconhecer os saberes e fazeres tradicionais dos povos africanos e valorizar a contribuição dos afro-brasileiros na construção de nossa sociedade dando visibilidade às suas bandeiras, às suas lutas e a suas conquistas, visa auxiliar na formação de indivíduos comprometidos com a igualdade e a justiça entre todos os cidadãos.

\section{REFERÊNCIAS BIBLIOGRÁFICAS}

ALVES, L. C. Oralidade e Axé na cozinha de Santo: perspectivas sobre a nação Ketu. In: Encontro de Gastronomia, Cultura e Memória, 2016, Rio de Janeiro .Anais do Encontro de Gastronomia, Cultura e Memória, Rio de Janeiro: 2016. Disponível em: 〈http://gcm.gastronomia.ufrj.br/arquivos-anais/Anais_IEGCM_2016.pdf\#page=19>. Acesso em: 13 abr. 2020.

BHABHA, H. K. O local da cultura. Belo Horizonte: editora UFMG, 2007

BRANDÃO, A. P. (coordenação). A Cor da Cultura - Saberes e Fazeres - Modos de Interagir. Fundação Roberto Marinho: Rio de Janeiro, 2006. 
BRANDÃO, Carlos Rodrigues;BORGES, Maristela Correa. Pesquisa Participante: um momento da educação popular. Rev. Ed. Popular, Uberlândia, v. 6, p.51-62. jan./dez. 2007.

BUENO, S. Dicionário Global Escolar Silveira Bueno. 5a. ed. São Paulo: Global Editora, 2007.

FREIRE, Paulo. Pedagogia da autonomia: saberes necessários à prática educativa. 5 . ed.Rio de Janeiro: Paz e Terra, 1996.

D’AMBRÓSIO, U.. Sociedade, cultura, matemática e seu ensino. Rev. Educação e Pesquisa, São Paulo, v. 31, n. 1, p. 99-120, jan./abr. 2005.

DOBAL, W. L. M.. Narrativas espaciais do Quilombo dos Alpes/ Porto Alegre/ RS: instrumento de encrespamento do ensino de Geografia, na busca de uma educação territorial antirracista. Porto Alegre: Universidade Federal do Rio Grande do Sul, 2015, 57 p. Trabalho de Conclusão de Curso, UFRGS, Porto Alegre, 2015.

HALL, Stuart. Da Diáspora: identidades e mediações culturais. Belo Horizonte: Editora UFMG; Brasília: Representação da Unesco no Brasil, 2018.

HARARI, YuvalNoah. Sapiens: Uma breve história da humanidade. $35^{\mathrm{a}}$ ed. Porto Alegre: L\&PM editora, 2018.

NASCIMENTO, L. A.; RAMOS, M. M. A memória dos velhos e a valorização da tradição na literatura africana: algumas leituras. Revista Crítica Cultural,Palhoça (SC), v. 6, n. 2, p. 453-467, jul/dez, 2011.

PEREIRA, R. P. O jogo africano 5 mancala e o ensino de matemática em face da Lei 10.639/03. 2011.156f. Dissertação (Mestrado em Educação) - Universidade Federal do Ceará, Faculdade de Educação, Programa de Pós-graduação em Educação Brasileira, Fortaleza-CE, 2011.

SANTOS, L. B. A etnomatemática e as relações étnico-raciais. Nganhu - Revista NeabiCp2 e Geparrei, Rio de Janeiro, vol. 1, n. 1, p. 148-161 , 2018.

TRINDADE, A. Valores civilizatórios afro-brasileiros e Educação Infantil: uma contribuição afro-brasileira. Modos de brincar: cadernos de saberes, fazeres e atividades. A Cor da Cultura, 2010. Disponível em http://www.acordacultura.org.br/, acessado em 28/09/2020 